\title{
Development and validation of a professionalism assessment scale for medical students
}

\author{
Zalika Klemenc-Ketis, Helena Vrecko
}

Department of Family Medicine, Faculty of Medicine, Taborska 8, 2000 Maribor, Slovenia

Correspondence: Zalika Klemenc-Ketis Kersnikova, 13320 Velenje, Slovenia. Email: zalika.klemenc.ketis@gmail.com

Accepted: October 25, 2014

\begin{abstract}
Objectives: To develop and validate a scale for the assessment of professionalism in medical students based on students' perceptions of and attitudes towards professionalism in medicine.

Methods: This was a mixed methods study with undergraduate medical students. Two focus groups were carried out with 12 students, followed by a transcript analysis (grounded theory method with open coding). Then, a 3round Delphi with 20 family medicine experts was carried out. A psychometric assessment of the scale was performed with a group of 449 students. The items of the Professionalism Assessment Scale could be answered on a five-point Likert scale.
\end{abstract}

Results: After the focus groups, the first version of the PAS consisted of 56 items and after the Delphi study, 30 items remained. The final sample for quantitative study consisted of 122 students (27.2\% response rate). There were 95 (77.9\%) female students in the sample. The mean age of the sample was $22.1 \pm 2.1$ years. After the principal component analysis, we removed 8 items and produced the final version of the PAS (22 items). The Cronbach's alpha of the scale was 0.88 . Factor analysis revealed three factors: empathy and humanism, professional relationships and development and responsibility.

Conclusions: The new Professionalism Assessment Scale proved to be valid and reliable. It can be used for the assessment of professionalism in undergraduate medical students.

Keywords: Ethics, professional, students, validation studies

\section{Introduction}

Professionalism can be defined as a collection of attitudes, values, behaviours and relationships that act as the foundation of the health professional's contract with society. ${ }^{1}$ It is one of the most important non-clinical topics learned and taught at all levels of medical education., ${ }^{2,3}$

In many curricula, at different levels of education, professionalism is a part of a hidden agenda. ${ }^{4}$ This means that it is not present in the form of a separate subject but is often coincidentally instilled into other subjects - usually without clear learning objectives. Students therefore usually learn about it in a rather roundabout manner and rarely get assessed on what they have learned. ${ }^{5}$

Professionalism is best taught in clinical settings (i.e. in family medicine practices, hospitals etc.) through rolemodelling of teachers. ${ }^{6,7}$ There, students can observe the behaviour of the physicians, their interactions with patients and members of the professional team, and their actions which reflect professional norms. ${ }^{8}$ It is known that students entering medical school already possess some attitudes towards professionalism gained from previous experience with the medical system and physicians. ${ }^{9}$ It has already been shown that lower grade medical students are more oriented towards professionalism than those in subsequent study years, and without appropriate teaching interventions this can decline through medical school. ${ }^{7}$ Students who interacted with consultants, colleagues and clinical staff during their clinical years were found to develop their sense of professionalism. ${ }^{10}$

As assessment is a necessary part of education, ${ }^{11,12}$ assessment of professionalism is also necessary. However, changes in professional behaviour (like changes in any type of behaviour) are difficult to assess. ${ }^{13,14}$ So far, many studies have tried to assess the professionalism of medical students at different levels. ${ }^{7,15-20}$ These studies have shown that students and trainees do have a clear insight into professionalism. Undergraduate students cited the following aspects of professionalism as important: confidentiality, good medical knowledge, practical skills, ${ }^{18}$ accountability to patients, respect for patients and their families, integrity, and prudence. ${ }^{21}$ Similar professional features were also recognized by trainees, which emphasized accountability 
and respect as essential characteristics of a professional physician. $^{22}$

On the other hand, previous studies have shown that students can have different perceptions of the importance or characteristics of the elements of professionalism. In a study from the UK, ${ }^{18}$ students also put forward punctuality, hygiene and appearance as being important, although these factors are rarely cited in the literature. It is therefore important to incorporate students' opinions about professionalism into research in this field. However, the assessment scales or questionnaires used in most previous studies were constructed on the basis of definitions of professionalism from the literature or on the opinions and attitudes of expert teachers.

We wanted to develop and validate a scale for the assessment of professionalism in medical students, based on students' perceptions of and attitudes towards professionalism in medicine. At the Faculty of Medicine in Maribor, students begin clinical experience in their third year. During their first year, they engage in problem-based learning during which they occasionally touch on the themes of ethics and professionalism. ${ }^{23}$ It is known that students entering medical school already possess some attitudes towards professionalism gained from previous experience with the medical system and physicians. ${ }^{9}$ We therefore decided to engage students from the first and the fifth year, in order to detect all possible attitudes towards professionalism.

\section{Methods}

\section{Study design}

This study had two parts and was performed in June 2013. The first part was a qualitative study, based on focus groups and a Delphi survey. The second part was a cross-sectional observational study.

\section{Participants}

This study was carried out with medical students of the Maribor Medical School, Slovenia, with the help of Slovenian family medicine experts. The study was approved by the National Ethics Board.

\section{Sampling size and sampling methods}

In the qualitative part, we carried out two focus groups and the Delphi survey. The first focus group consisted of five first-year medical students (three women and two men), each 19 years old. The second group consisted of seven fifth-year medical students (two men and five women), all 23 years old. Both focus groups were moderated by one of the researchers (HV) and observed by the second researcher (ZKK).

The expert pool for the Delphi survey consisted of 20 family medicine experts, mainly teachers of family medicine and working family physicians. Ten to fifteen Delphi participants are usually sufficient if their background is homogeneous. ${ }^{24}$

The quantitative part was designed as a cross-sectional observational study. It was carried out at the Maribor Medical School in Slovenia where all the students in each of the 6 years $(\mathrm{N}=449)$ who enrolled on the course for the study year 2013/2014 were contacted by email and asked to complete the questionnaire.

\section{Data collection}

The participants of the focus groups discussed several questions (Box 1).

Box 1: The questions discussed in focus groups

- What does the term medical professionalism mean to you?

- In your opinion, which factors are involved in medical professionalism?

- Is medical professionalism, in your opinion, part of the work of a physician, and why?

- In your opinion, how do physicians express their professionalism?

- Why is it important that physicians cherish the elements of professionalism?

- In what ways are professionalism and professional expertise associated?

A 3-round Delphi survey was conducted to validate and establish the consensus on a final professionalism assessment scale (PAS). Typically, two or more rounds of Delphi must be conducted in order to reach a valid consensus. ${ }^{25}$ All the rounds of Delphi were presented through GoogleDoc sheets, an online survey method. The invitations were sent out by email. In the first round of Delphi, the experts were asked to mark those items which should be part of the PAS in their present formulation, those items which should not be a part of a professionalism scale, and those items that should be a part of the scale but needed editing. The researchers decided that an item should reach $90 \%$ or higher agreement to be included in the second version of the PAS. In the second round of Delphi, the experts were asked to mark the items on a 9-point Likert scale for clarity and necessity. For clarity, 1 point meant that the item was completely unclear and totally ambiguous and 9 points meant that the item was completely clear and totally unambiguous. For necessity, 1 point meant that the item was completely unnecessary for assessment of professionalism and 9 points meant that the item was absolutely necessary for assessment of professionalism. The researchers decided that the items' mean scores for clarity and necessity should be 7 points or more for them to be included in the third version of the PAS.

In the third round of Delphi, the experts were asked to provide a simple yes/no response approving the changes made in both previous rounds and the scale as a whole. Again, a 90\% level of agreement was sought. 
In the quantitative part, the participants completed the questionnaires and returned them to the researcher. The questionnaires were anonymous so that the identity of the students could not be determined. The PAS's items could be answered on a 5-point Likert scale; 1 point meant that the participant strongly disagreed with the item and 5 points meant that the participants strongly agreed with the item.

\section{Data analysis}

The interviews derived from the two focus groups were recorded and transcribed into word documents. The transcripts were independently evaluated by both researchers (HV and ZKK). Segments of transcripts identified as important were marked as 'verbatims' which served as items for the development of the PAS. A grounded theory method with open coding was applied and saturation was reached. The data from the quantitative part were analysed by the SPSS 13.0 (SPSS Inc., Chicago, IL, USA). First we performed a principal component analysis to remove any redundant or unnecessary items. The items were removed if the loadings were too weak (less than 0.39 ) or too general (more than 0.40 on more than one factor). ${ }^{26}$ The item was also removed if an increase of Cronbach's alpha of $>0.10$ within the factor occurred after the deletion of the item. ${ }^{27}$ We determined the scale's reliability by calculating Cronbach's alpha.

Due to a high Cronbach's alpha value, we calculated a composite score. We used a Baker \& Hearnshaw equation ${ }^{28}$ $\left[\left(\sum\right.\right.$ items $\left.\left.\left.1-22\right) \times 100 /(5 \times 22)\right] \times 1.25-25\right)$ to range the scale's score from 0 to 100 . In this equation, $\Sigma$ items $1-22$ represents the sum of the scores of 22 PAS items, 5 represents the maximum score points of each item and 22 represents the number of PAS items. The other numbers are needed for mathematical purposes in order to range the scale's score from 0 to 100 . For determining the scale's factors, we performed a factor analysis with Equamax using the Kaiser normalization rotation method. We also calculated the Kaiser-Meer-Olkin (KMO) measure of sampling adequacy and Bartlett's test of sphericity. For each factor, we calculated the Cronbach's alpha. To determine the content and face validity, the Delphi method with experts (see above) was performed.

\section{Results}

\section{Qualitative part}

After the focus groups and the qualitative analysis, the first version of the PAS consisted of 56 items. In the first Delphi round, 12 (600\%) experts provided answers. Based on their answers, 21 out of the original 56 items were excluded, and 21 items were edited, leaving 35 items in the second version of the PAS. In the second Delphi round, 10 (50\%) experts provided answers. Based on their answers, 5 out of the 35 items were excluded, so the third version of the PAS contained 30 items. In the third Delphi round, 10 (50\%) experts provided answers, and based on them, no further items were excluded, leaving 30 items in the post-Delphi version of the PAS.

\section{Quantitative part}

The final sample consisted of 122 students from all 6 years of study (27.2\% response rate). There were 95 (77.9\%) female students in the sample. The mean age of the sample was $22.1 \pm 2.1$ years. There were $9(7.4 \%)$ students in the first, $28(23 \%)$ in the second, $30(24.6 \%)$ in the third, 9 $(7.4 \%)$ in the fourth, $10(8.2 \%)$ in the fifth and $36(29.4 \%)$ in the sixth study year.

After the principal component analysis, we removed 8 items and came up with a final version of PAS consisting of 22 items.

The scale's Cronbach's alpha was 0.88 (Table 1). The mean total score was $90.9 \pm 8.9$ points and the median was 93.1 points. The minimum was 32 and the maximum 100 points. The KMO value was 0.846 and Bartlett's test was highly significant $(\mathrm{p}<0.001)$.

Factor analysis revealed three factors: empathy and humanism (10 items), professional relationship and development ( 8 items) and responsibility (4 items) (Table 2 ) which explained $46.8 \%$ of the variance; the first factor explained $32.7 \%$, the second $7.8 \%$ and the third $6.3 \%$. Cronbach's alpha of the first factor was 0.84 , of the second 0.78 and of the third 0.60 .

Several items were perceived to be of the highest importance: a current bad mood of the physician should not affect the management of patients; the physician should have a respectful relationship towards the patients; it is the physician's duty to present his/her professional opinion to the patient in such a way that the patient can understand and accept it; and it is the physician's obligation to protect the confidentiality of the patient. Two items were perceived to be the least important: the physician cannot always know what is best for each patient, and the physician should tell the patient frankly if there is something he/she does not know (Table 3).

\section{Discussion}

\section{Summary of main findings}

This study proved the new PAS to be reliable and valid when assessing professionalism attitudes in undergraduate medical students. Three factors - empathy/humanism, professional relationship/development, and responsibility emerged as the key factors of the scale. It seems that attitudes of undergraduate students towards professionalism are associated with gender and age.

\section{Comparison to other tools}

Our tool for the assessment of professionalism proved to have good internal reliability. Also, it has good construct validity as the corrected item correlation was above 0.40 for each item. 
Table 1: Professionalism assessment scale: item analysis

\begin{tabular}{|c|c|c|c|c|}
\hline Factor & Item & $\begin{array}{l}\text { Corrected item-total } \\
\text { correlation }\end{array}$ & $\begin{array}{l}\text { Cronbach's alpha if } \\
\text { item deleted }\end{array}$ & $\begin{array}{c}\text { Factor's } \\
\text { Cronbach's alpha }\end{array}$ \\
\hline \multirow{10}{*}{$\begin{array}{l}\text { Factor } 1 \text { - Empathy } \\
\text { and humanism }\end{array}$} & $\begin{array}{l}\text { When managing patients the physician should put aside his/her } \\
\text { prejudices. }\end{array}$ & 0.448 & 0.878 & 0.84 \\
\hline & $\begin{array}{l}\text { Current bad mood of the physician should not affect the } \\
\text { management of patients. }\end{array}$ & 0.479 & 0.879 & \\
\hline & $\begin{array}{l}\text { Physician should have a respectful relationship towards the } \\
\text { patients. }\end{array}$ & 0.590 & 0.876 & \\
\hline & $\begin{array}{l}\text { Physician should have a respectful relationship towards co- } \\
\text { workers. }\end{array}$ & 0.649 & 0.873 & \\
\hline & $\begin{array}{l}\text { Physician should do his/her best to help the patient in every } \\
\text { consultation. }\end{array}$ & 0.530 & 0.876 & \\
\hline & $\begin{array}{l}\text { Physician should adapt to the level of the patient's understand- } \\
\text { ing. }\end{array}$ & 0.425 & 0.879 & \\
\hline & Physician should be a good role model for students. & 0.619 & 0.875 & \\
\hline & Each patient deserves individual management. & 0.555 & 0.876 & \\
\hline & $\begin{array}{l}\text { It is the physician's obligation to protect the confidentiality of the } \\
\text { patient. }\end{array}$ & 0.507 & 0.878 & \\
\hline & The physician should show interest in the patient. & 0.620 & 0.873 & \\
\hline \multirow{8}{*}{$\begin{array}{l}\text { Factor } 2 \text { - } \\
\text { Professional } \\
\text { relationship and } \\
\text { development }\end{array}$} & $\begin{array}{l}\text { Physician should constantly engage in continuous professional } \\
\text { education. }\end{array}$ & 0.483 & 0.883 & 0.78 \\
\hline & $\begin{array}{l}\text { Physician should set clear limits in patient communication and } \\
\text { be able to say 'no'. }\end{array}$ & 0.424 & 0.882 & \\
\hline & $\begin{array}{l}\text { Physician should be able to set a clear line between private and } \\
\text { professional life. }\end{array}$ & 0.544 & 0.875 & \\
\hline & $\begin{array}{l}\text { Physician should aspire to professional relationships in his/her } \\
\text { team. }\end{array}$ & 0.595 & 0.874 & \\
\hline & $\begin{array}{l}\text { A lot of clinical knowledge is not sufficient to be a good } \\
\text { physician. }\end{array}$ & 0.568 & 0.874 & \\
\hline & $\begin{array}{l}\text { Physician-patient communication is the basis of patient } \\
\text { management. }\end{array}$ & 0.642 & 0.873 & \\
\hline & $\begin{array}{l}\text { Physician should also try to understand the patient's non- } \\
\text { medical problems (i.e. poor financial status, family relationship } \\
\text { problems) and include them in the consultation. }\end{array}$ & 0.659 & 0.871 & \\
\hline & It is acceptable that the physician can make mistakes. & 0.428 & 0.883 & \\
\hline \multirow{4}{*}{$\begin{array}{l}\text { Factor } 3 \text { - } \\
\text { responsibility }\end{array}$} & Physician should not judge the patient by appearances. & 0.585 & 0.874 & 0.60 \\
\hline & $\begin{array}{l}\text { It is the physician's duty to present his/her professional opinion } \\
\text { to the patient in such a way that the patient can understand and } \\
\text { accept it. }\end{array}$ & 0.427 & 0.880 & \\
\hline & The physician cannot always know what is best for each patient. & 0.496 & 0.877 & \\
\hline & $\begin{array}{l}\text { The physician should tell the patient frankly if there is something } \\
\text { he/she does not know. }\end{array}$ & 0.441 & 0.891 & \\
\hline
\end{tabular}

This indicates that the PAS can be used as a whole and its total score can be calculated when detecting possible associations or correlations with different variables. The internal reliability of other scales for the assessment of professionalism in other studies ranged from 0.71 to $0.86 .^{15}$, ${ }^{16,29,30}$ Our tool seems to cover several professional themes which loaded to three factors: empathy/humanism, professional relationship/development, and responsibility. A USA charter of professionalism, published in 2002, described three fundamental principles of professionalism: patient welfare (altruism, trust, patient interest), patient autonomy (honesty, patient empowerment) and social justice. ${ }^{31}$ In addition to these principles, our tool also recognised the need and self-awareness of medical students for continuous professional education. Factor analysis of other tools revealed a different number of factors: from three ${ }^{29}$ to as many as eight. ${ }^{21}$ It seems that the number of factors does not affect the comprehensiveness of the tools, as even though some of the tools have a smaller number of factors, they still cover most professionalism features..$^{29,30}$

The students scored high on the PAS, and it therefore seems that they are aware of medical professionalism. The most highly scored items came from the empathy/humanism domain. This is in line with the work of AlEraky et $\mathrm{al}^{16}$ and Tsai et al. ${ }^{21}$ On the other hand, the lowest scored items came from the domain of responsibility, which is not in line with Al-Eraky et al. ${ }^{16}$ However, El-Eraky et al ${ }^{16}$ studied medical students and interns, which might have accounted for this difference. At the undergraduate level, the students may not yet be fully aware of their responsibilities as physicians.

\section{Factor 1}

The first factor covered empathy and humanism and explained most of the variance. Its internal reliability was good. Empathy and humanism factors have also been recognised in other tools as upholding principles of integri 
ty, ${ }^{15}$ respect and relationships with others, ${ }^{15}$ honour/integrity, ${ }^{16,32}$ equity, ${ }^{32}$ commitment to care, ${ }^{21}$ patientoriented issues, ${ }^{21}$ and respect for others. ${ }^{21}$ Empathy and humanism items are also one of the fundamental principles of medical professionalism. ${ }^{31}$ It seems that empathy and humanism items can be found in most professionalism assessment scales, but in different factors; nevertheless, this implies that these professionalism features are fundamental and are always recognised by students, and so should be a part of every professionalism assessment scale.

Table 2. Factor analysis of professionalism assessment scale

\begin{tabular}{|c|c|c|c|}
\hline Item & $\begin{array}{l}\text { Factor } 1 \text { - empathy } \\
\text { and humanism }\end{array}$ & $\begin{array}{l}\text { Factor } 2 \text { - professional } \\
\text { relationship and development }\end{array}$ & $\begin{array}{l}\text { Factor } 3- \\
\text { responsibility }\end{array}$ \\
\hline \multirow{2}{*}{$\begin{array}{l}\text { When managing patients the physician should put aside his/her prejudices. } \\
\text { Current bad mood of the physician should not affect the management of } \\
\text { patients. }\end{array}$} & 0.511 & 0.217 & 0.101 \\
\hline & 0.493 & 0.090 & 0.370 \\
\hline Physician should have a respectful relationship towards the patients. & 0.818 & 0.103 & 0.130 \\
\hline Physician should have a respectful relationship towards co-workers. & 0.702 & 0.285 & 0.187 \\
\hline Physician should do his/her best to help the patient in every consultation. & 0.486 & 0.122 & 0.417 \\
\hline Physician should adapt to the level of the patient's understanding. & 0.368 & 0.258 & 0.187 \\
\hline Physician should be a good role model for students. & 0.652 & 0.411 & 0.025 \\
\hline Each patient deserves individual management. & 0.633 & 0.041 & 0.369 \\
\hline It is the physician's obligation to protect the confidentiality of the patient. & 0.592 & 0.071 & 0.299 \\
\hline The physician should show interest in the patient. & 0.551 & 0.211 & 0.407 \\
\hline \multirow{2}{*}{$\begin{array}{l}\text { Physician should constantly engage in continuous professional education. } \\
\text { Physician should set clear limits in patient communication and be able to } \\
\text { say 'no'. }\end{array}$} & 0.051 & 0.415 & 0.155 \\
\hline & 0.045 & 0.686 & -0.063 \\
\hline $\begin{array}{l}\text { Physician should be able to set a clear line between private and profes- } \\
\text { sional life. }\end{array}$ & 0.287 & 0.556 & 0.204 \\
\hline Physician should aspire to professional relationships in his/her team. & 0.470 & 0.593 & 0.011 \\
\hline A lot of clinical knowledge is not sufficient to be a good physician. & 0.439 & 0.472 & 0.147 \\
\hline Physician-patient communication is the basis of patient management. & 0.493 & 0.481 & 0.223 \\
\hline $\begin{array}{l}\text { Physician should also try to understand the patient's non-medical problems } \\
\text { (i.e. poor financial status, family relationship problems) and include them in } \\
\text { the consultation. }\end{array}$ & 0.296 & 0.504 & 0.453 \\
\hline It is acceptable that the physician can make mistakes. & -0.169 & 0.629 & 0.311 \\
\hline & 0.363 & 0.247 & 0.527 \\
\hline $\begin{array}{l}\text { It is the physician's duty to present his/her professional opinion to the } \\
\text { patient in such a way that the patient can understand and accept it. }\end{array}$ & 0.197 & -0.012 & 0.724 \\
\hline \multirow{2}{*}{$\begin{array}{l}\text { The physician cannot always know what is best for each patient. } \\
\text { The physician should tell the patient frankly if there is something he/she } \\
\text { does not know. }\end{array}$} & 0.236 & 0.299 & 0.473 \\
\hline & -0.120 & 0.118 & 0.620 \\
\hline $\begin{array}{l}\text { Eigenvalue } \\
\text { Variance }(\%)\end{array}$ & $\begin{array}{c}7.463 \\
32.720\end{array}$ & $\begin{array}{l}1.510 \\
7.781\end{array}$ & $\begin{array}{l}1.316 \\
6.268\end{array}$ \\
\hline
\end{tabular}

\section{Factor 2}

The second factor covered professional relationships and development. Its internal reliability was good. These items were also recognised in other tools as relationship with others, ${ }^{15}$ duty/accountability, ${ }^{16,32}$ excellence/autonomy, ${ }^{16}$ duty, ${ }^{32}$ habit of professional practice ${ }^{21}$ and respect for others. ${ }^{21}$ One could anticipate that undergraduate students might not be fully aware of the need for professional development as this is usually a feature of long-life learning. ${ }^{33}$ However, according to the results of our and similar studies, ${ }^{16,21}$ this is not the case.

\section{Factor 3}

The third factor covered responsibility. Its internal reliability was acceptable. Responsibility was recognised also in other tools as responsibility, ${ }^{15}$ accountability, ${ }^{15}$ altruism, ${ }^{16,32}$ righteous ${ }^{21}$ and rule-abiding. ${ }^{21}$ Responsibility is one of the fundamental features of a professional physician. This was also recognized by the students in the qualitative part of the study, even though later on these items were perceived as the least important.

\section{Implications of the study}

Our study indicates that a valid and reliable scale can be developed from the analysis of students' attitudes towards medical professionalism. Factor analysis showed that the PAS covers the most essential features of medical professionalism. When dealing with scales for the assessment of professionalism, we have to bear in mind that no single tool can include all traits and behaviours of medical professionalism, as this is a complex construct ${ }^{16}$ and can also be perceived differently by different populations.

The PAS has been designed and tested in a sample of undergraduate medical students. As it has been derived from the qualitative analysis of the interviews with this population, we can claim that it can be successfully used with undergraduate medical students. It can be used to assess the students' attitudes towards professionalism at the beginning of the study and in formative assessment. It can also be used for students' self-assessment. Further studies are needed to determine its use in medical education and also in other populations, such as residents, practising physicians, and also in patients, nurses and other healthcare professionals.

The bivariate analysis showed some associations with gender and age/study year. Female students, older students and those in later study years scored higher. The latter was expected, as medical education should constantly work on building a professional physician. However, further studies are needed to confirm such associations. 
Table 3. Respondents' evaluation of professionalism assessment scale

\begin{tabular}{|c|c|c|c|c|}
\hline Item & $\begin{array}{l}\text { Mean score } \pm \\
\text { standard deviation }\end{array}$ & $\begin{array}{l}\text { Median } \\
(\text { min, max })\end{array}$ & Skewness & Kurtosis \\
\hline When managing patients the physician should put aside his/her prejudices. & $4.7 \pm 0.6$ & $5.0(2,5)$ & -2.391 & 7.687 \\
\hline Current bad mood of the physician should not affect the management of patients. & $4.9 \pm 0.4$ & $5.0(3,5)$ & -2.728 & 7.086 \\
\hline Physician should have a respectful relationship towards the patients. & $4.9 \pm 0.4$ & $5.0(1,5)$ & -8.892 & 86.616 \\
\hline Physician should have a respectful relationship towards co-workers. & $4.8 \pm 0.6$ & $5.0(1,5)$ & -3.229 & 13.777 \\
\hline Physician should constantly engage in continuous professional education. & $4.6 \pm 0.7$ & $5.0(1,5)$ & -2.467 & 7.790 \\
\hline Physician should do his/her best to help the patient in every consultation. & $4.8 \pm 0.5$ & $5.0(2,5)$ & -2.610 & 7.682 \\
\hline Physician should not judge the patient by appearances. & $4.6 \pm 0.7$ & $5.0(2,5)$ & -2.092 & 3.999 \\
\hline Physician should adapt to the level of patient's understanding. & $4.5 \pm 0.8$ & $5.0(1,5)$ & -1.802 & 3.928 \\
\hline Physician should set clear limits in patient communication and be able to say 'no'. & $4.6 \pm 0.7$ & $5.0(2,5)$ & -1.942 & 3.916 \\
\hline Physician should be a good role model for students. & $4.8 \pm 0.5$ & $5.0(2,5)$ & -2.950 & 10.293 \\
\hline Physician should be able to set a clear line between private and professional life. & $4.5 \pm 0.7$ & $5.0(2,5)$ & -1.570 & 2.236 \\
\hline Physician should aspire to professional relationships in his/her team. & $4.7 \pm 0.6$ & $5.0(2,5)$ & -1.902 & 3.071 \\
\hline A lot of clinical knowledge is not sufficient to be a good physician. & $4.6 \pm 0.8$ & $5.0(1,5)$ & -2.292 & 5.505 \\
\hline Physician-patient communication is the basis of patient management. & $4.7 \pm 0.6$ & $5.0(2,5)$ & -1.892 & 3.604 \\
\hline $\begin{array}{l}\text { Physician should also try to understand the patient's non-medical problems (i.e. } \\
\text { poor financial status, family relationship problems) and include them in the } \\
\text { consultation. }\end{array}$ & $4.5 \pm 0.8$ & $5.0(1,5)$ & -1.469 & 2.303 \\
\hline Each patient deserves individual management. & $4.8 \pm 0.5$ & $5.0(2,5)$ & -3.242 & 13.114 \\
\hline $\begin{array}{l}\text { It is the physician's duty to present his/her professional opinion to the patient in } \\
\text { such a way that the patient can understand and accept it. }\end{array}$ & $4.9 \pm 0.4$ & $5.0(3,5)$ & -2.862 & 7.968 \\
\hline $\begin{array}{l}\text { The physician cannot always know what is best for each patient. } \\
\text { It is the physician's obligation to protect the confidentiality of the patient. }\end{array}$ & $\begin{array}{l}4.1 \pm 0.9 \\
4.9 \pm 0.4\end{array}$ & $\begin{array}{l}4.0(1,5) \\
5.0(3,5)\end{array}$ & $\begin{array}{l}-0.772 \\
-3.054\end{array}$ & $\begin{array}{l}0.349 \\
9.330\end{array}$ \\
\hline The physician should show interest in the patient. & $4.6 \pm 0.7$ & $5.0(1,5)$ & -2.846 & 10.656 \\
\hline $\begin{array}{l}\text { The physician should tell the patient frankly if there is something he/she does not } \\
\text { know. }\end{array}$ & $3.9 \pm 1.1$ & $4.0(1,5)$ & -0.747 & -0.286 \\
\hline It is acceptable that the physician can make mistakes. & $4.6 \pm 0.8$ & $5.0(1,5)$ & -2.150 & 4.117 \\
\hline
\end{tabular}

\section{Limitations of the study}

The sample size was sufficient for the validation study; usually, a sample size should consist of at least 80 participants. ${ }^{34}$ However, some authors ${ }^{35}$ argue that an adequate sample should consist of at least 300 participants. In our study, the reliability and validity of the PAS indicates that the sample size was sufficient. Empathy was revealed as the main factor on the scale; due to the fact that most of the sample was female, this finding could be a consequence of a gender bias, so this result should be interpreted with care. Also, the response rate in quantitative part of the study was low, which could have affected the external validity of the study due to an auto-selection bias.

According to skewness and kurtosis, the distribution of the data was probably not normal, which further confirms that the sample could be auto-selected.

We carried out several rotations in factor analysis in order to get the best solution. In the end we chose the Equamax rotation which is also used when dealing with orthogonal items. Some items of the scale showed share loadings on at least two factors. We decided on where they should be placed according to the content of the factor itself. However, it is also true that professionalism items often overlap, as professionalism features are associated with each other and cannot be regarded as separate entities.

\section{Conclusion}

The new professionalism assessment scale proved to be valid and reliable. It can be used for the assessment of professionalism in undergraduate medical students in terms of summative and formative assessment and for self- assessment. Further studies are needed to determine its use in undergraduate settings and to study the associations of students' attitudes towards professionalism and the undergraduates' characteristics.

\section{Acknowledgements}

We thank all the students who participated in the study. We also thank Professor Janko Kersnik for his valuable advice.

\section{Conflict of Interest}

The authors declare that they have no conflict of interest.

\section{References}

1. Anon. Doctors in society: medical professionalism in a changing world. Report of a Working Party of the Royal College of Physicians of London. London: Royal College of Physicians of London; 2005.

2. Kersnik J, Wensing M. Improving the quality of care for patients with chronic diseases: what research and education in family medicine can contribute. Eur J Gen Pract. 2012;18(4):238-41.

3. Svab I. General practice teaching at the undergraduate level in Europe. Eur J Gen Pract. 1999;5:125-7.

4. Rogers DA, Boehler ML, Roberts NK, Johnson V. Using the hidden curriculum to teach professionalism during the surgery clerkship. J Surg Educ. 2012;69(3):423-7.

5. Novak-Antolic Z, Steblovnik L. Introducing multi-source feedback of trainees. Zdravstveno Varstvo. 2012;51(4):227-36.

6. Hilton S. Education and the changing face of medical professionalism: from priest to mountain guide? Br J Gen Pract. 2008;58(550):353-61.

7. Johnston JL, Cupples ME, McGlade KJ, Steele K. Medical students' attitudes to professionalism: an opportunity for the GP tutor? Educ Prim Care. 2011;22(5):321-7.

8. Birden H, Glass N, Wilson I, Harrison M, Usherwood T, Nass D. Teaching professionalism in medical education: a Best Evidence Medical Education (BEME) systematic review. BEME Guide No. 25. Med Teach. 2013;35(7):e1252-e66.

9. Hafferty FW. What medical students know about professionalism. Mt Sinai J Med. 2002;69(6):385-97. 
10. Eldeek BS, Ayuob NN, Alshawa LA, Al Sharif AT, Alshareef N, Bokhari RF. Impact of medical curriculum on conceptualization of professionalism by residents at a University Hospital, Jeddah, Saudi Arabia. J Egypt Public Health Assoc. 2012;87(3-4):45-50.

11. Svab I. Education in medicine. Zdravstveno Varstvo. 2012;51:225-6

12. Kersnik J. Learning and teaching to educate future GPs. Eur J Gen Pract. 2012;18(4):199-200.

13. Klemenc-Ketis Z, Kersnik J. Using movies to teach professionalism to medical students. BMC Med Educ. 2011;11:60.

14. Wilkinson JT, Wade WB, Knock LD. A blueprint to assess professionalism: results of a systematic review. Acad Med. 2009;84(5):551-8.

15. Kelley KA, Stanke LD, Rabi SM, Kuba SE, Janke KK. Cross-validation of an instrument for measuring professionalism behaviors. Am J Pharm Educ. 2011;75(9):179-.

16. Al-Eraky MM, Chandratilake M, Wajid G, Donkers J, van Merrienboer J. Medical professionalism: development and validation of the Arabian LAMPS. Med Teach. 2013;35 Suppl 1:S56-S62.

17. Byszewski A, Hendelman W, McGuinty C, Moineau G. Wanted: role models - medical students' perceptions of professionalism. BMC Med Educ. 2012;12:115.

18. Gale-Grant G, Gatter M, Abel P. Developing ideas of professionalism. Clin Teach. 2013;10(3):165-9.

19. Kelly M, O'Flynn S, McLachlan J, Sawdon MA. The clinical conscientiousness index: a valid tool for exploring professionalism in the clinical undergraduate setting. Acad Med. 2012;87(9):1218-24.

20. van de Camp K, Vernooij-Dassen M, Grol R, Bottema B. Professionalism in general practice: development of an instrument to assess professional behaviour in general practitioner trainees. Med Educ. 2006;40(1):43-50.

21. Tsai TC, Lin CH, Harasym PH, Violato C. Students' perception on medical professionalism: the psychometric perspective. Med Teach. 2007;29(2-3):128-34.

22. Gillespie C, Paik S, Ark T, Zabar S, Kalet A. Residents' perceptions of their own professionalism and the professionalism of their learning environment. J Grad Med Educ. 2009;1(2):208-15.
23. Neville AJ. Problem-based learning and medical education forty years on. A review of its effects on knowledge and clinical performance. Med Princ Pract. 2009;18(1):1-9.

24. Bowling A. Research methods in health: investigating health and health services. Maidenhead, PA: Open University Press; 2003.

25. Jones J, Hunter D. Using the Delphi and nominal group technique in health service research. In: Pope C, Mays N, editors. Qualitative research in health care. Bristol: BMJ Books; 2000.

26. Rattray J, Jones MC. Essential elements of questionnaire design and development. J Clin Nurs. 2007;16(2):234-43.

27. Ferketich S. Focus on psychometrics: aspects of item analysis. . Res Nurs Health. 1991;14:165-8.

28. Baker R, Hearnshaw H. A method for surveying patient satisfaction audit protocol PS1. Leicester: Eli Lilly National Cinical Audit Centre; 1996.

29. Arnold EL, Blank LL, Race KE, Cipparrone N. Can professionalism be measured? The development of a scale for use in the medical environment. Acad Med. 1998;73(10):1119-21.

30. Symons AB, Swanson A, McGuigan D, Orrange S, Akl EA. A tool for self-assessment of communication skills and professionalism in residents. BMC Med Educ. 2009;9:1.

31. Brennan T, Blank L, Kimball H, Smelser N, Copeland R, Lavizzo R, et al. Medical professionalism in the new millennium: a physicians' charter. Clin Med. 2002;2(2):116-8.

32. Blackall GF, Melnick SA, Shoop GH, George J, Lerner SM, Wilson PK, et al. Professionalism in medical education: the development and validation of a survey instrument to assess attitudes toward professionalism. Med Teach. 2007;29(2-3):e58-e62.

33. Czabanowska K, Klemenc-Ketis Z, Potter A, Rochfort A, Tomasik T, Cziszar J, et al. Development of a competency framework for quality improvement in family medicine: a qualitative study. J Contin Educ Health Prof. 2012;32(3):174-80.

34. Cohen J. Statistical power analysis. Hillsdale, NJ: Erlbaum; 1988.

35. Worthington R, Whittaker T. Scale development research: a content analysis and recommendations for best practices. Counseling Psychologist. 2006;34:806-38. 